\title{
Patients at the centre: in our practice, and in our use of language
}

lints a formerly widespread approach to medical decision making, physicians made a diagnosis, considered the management alternatives, and informed patients what would be done to help them. Decision making rested exclusively in the physicians' domain.

This parental model of patient care challenged clinicians to interpret what was best for their patients. How much benefit must a treatment offer before it was worth subjecting a patient to its short term side effects, long term risks, inconveniences, and costs? With the clinician at the centre of decision making, the question was whether a treatment effect was "clinically relevant." Even in the discipline of health related quality of life measurement, investigators sought the "minimal clinically important difference."

The parental model has its strengths, and in the past it is very likely that many patients preferred leaving the decisions to their doctors, particularly when the knowledge gap between physicians and the lay public was greater. Consider, for instance, the results of a survey of 2472 patients with chronic disease (hypertension, diabetes, heart failure, myocardial infarction, or depression) completed between 1986 and 1990. In response to the statement: "I prefer to leave decisions about my medical care up to my doctor," 17.1\% strongly agreed, 45.5\% agreed, $11.1 \%$ were uncertain, $22.5 \%$ disagreed, and only $4.8 \%$ strongly disagreed. ${ }^{1}$ Cultural changes since the 1950 s suggest that in the more distant past, the percentage preferring to leave decisions up to the doctor was even greater. For example, in the survey that generated these data, older patients were less inclined to prefer an active decision making role than younger respondents.

Parental approaches to decision making have limitations related to physicians' evaluation of how patients value benefits and risks. One issue is physicians' tendency to assume that physiological outcomes will lead to improvements in mortality and quality of life. Physicians are strongly influenced by the scientific tradition of medicine, a tradition that gained preeminence soon after the turn of the 20th century. This scientific tradition led investigators, and subsequently clinicians, to focus on what was objectively and immediately measurable. The physiology underlying this science involved a clear notion of causal connections. A drug increased inotropy or decreased the afterload against which the failing heart had to pump, the ejection fraction increased, the cardiac output increased, tissue perfusion improved, and the pulmonary wedge pressure fell. It was natural to assume that the patient would feel better and live longer. What change in inotropy or reduction in afterload would lead to the desirable consequences required judgement. That is, how big a difference was required for "clinical relevance?"

The physiological model of medical decisions remains prominent. When medical students and residents reply to questions about why they are prescribing an angiotensin converting enzyme inhibitor, rather than citing an anticipated mortality reduction, they usually note its afterload reducing properties. In a parallel persistence, physicians and medical authors considering whether the magnitude of a treatment effect is important continue to frame the issue as one of "clinical relevance." 23

We now know that some drugs that obliterate asymptomatic ventricular arrhythmias increase fatal arrhythmias, ${ }^{4}$ some drugs that improve lipid profiles fail to reduce cardiovascular risk, ${ }^{5}$ and some potent inotropes and afterload reducers increase mortality in heart failure. ${ }^{6-10}$ Physiological $^{-1}$ rationale usually works well in predicting patient benefit, but in an appreciable minority of situations, it yields predictions that prove disastrously incorrect.

Even if physicians resist assumptions about physiological outcomes, they may make value judgements that differ from those of their patients. Faced with the same critically ill patient, for instance, one clinician will advocate withdrawal of life support, and another, full aggressive interventions. ${ }^{11}$ Facing the decision concerning anticoagulation in atrial fibrillation, clinicians are more concerned about bleeding risk, and place less weight on the associated stroke reduction, than patients. $^{12}$

In some parts of the world, including North America and Europe, the process of medical decision making is changing. Increasing general levels of education, the advent of the internet and the resulting access to medical information, and an increasingly litigious and consumerist environment have all increased patients' desire to play a more active role in decision making. In 1 recent study of patients with node negative breast cancer who were considering adjuvant chemotherapy, $84 \%$ of 171 women preferred an independent or shared role in decision making..$^{13}$ Shared decision making and patient centredness have become attractive approaches to resolving the profusion of challenging choices facing patients and clinicians. ${ }^{14-16}$

This is not to say that there are no dangers in preeminent patient decision making, that the ideal approach to decision making in practice has been fully defined, or that we are anywhere near the application of consistent shared decision making in clinical practice. In terms of optimal approaches to shared decision making, limitations include our ignorance of the best ways of communicating information and uncertainty to patients, and the risks that patients will misunderstand and as a result choose management strategies not in their best interests. In terms of implementing shared decision making, time constraints severely limit clinicians' opportunities to elicit and fully appreciate patients' perspectives. Understanding the process of decision making is given little attention in medical curricula, and clinicians may not fully appreciate the importance of values and preferences in decision making, and the potential differences between their preferences and those of their patients.

Shared decision making-like evidence-based medicine when in its initial phases, and perhaps even today-also faces risks for misunderstanding. Shared decision making includes the physician as an active partner, engaged in dialogue and exploration with the patient. When patients decide not to take an effective therapy they may not be fully aware of the consequences, and may thus be acting against their own best 
interests. The clinician's role in these circumstances is to try to understand the patient's decision (are they choosing not to take an effective therapy because of its cost or are they misconstruing the potential benefits, risks, or inconveniences?). When a decision is made because of misunderstanding, the clinician's role is to provide clarification and additional information that will allow the patient to make an informed decision. Furthermore, whether the patient's preference is for euthanasia or non-therapeutic use of narcotics, clinicians are never under obligation to act in ways they find morally, ethically, or even legally problematic.

These challenges notwithstanding, shared decision making is gaining clearer definition, and patients' voices calling for a greater say in medical decisions are increasingly audible. Research is beginning to address issues of effectively ascertaining patients' values and preferences and communicating information. ${ }^{17}$ Our language, however, is lagging behind.

Language reflects the way we think and often conditions the way we think and behave. Clinicians who find arguments concerning the limitations of physiological endpoints compelling, and who agree with the preeminence of patient values and preferences, may want to modify their language accordingly. Such clinicians might want to recommend interventions not when the magnitude of the effect is "clinically relevant," but when it is "patient important."

When we state that an intervention alters "patient important" outcomes, we are less likely to slip back into risky physiological thinking. Cardiac ejection fraction or laboratory exercise capacity may be clinically relevant; they are not "patient important." Use of "patient important" directs our attention appropriately when we apply the critical appraisal criterion, "have the investigators considered all relevant outcomes?" to a randomised trial. Use of "patient important" reminds us to cast a sceptical eye on clinical practice guidelines, and not neglect the critical appraisal criterion that demands that guideline developers make underlying values and preferences explicit.

Other commentators have noted the limitations of "clinical relevance" and suggested alternative terms, including "patient oriented"18 and "personal significance." ${ }^{19}$ The latter term takes our perspective beyond that of the patient. Personal significance might lead us to consider the patient's family members, or the individual involved in a community screening programme.

In contrast, Richard Peto has used the term "humanly important" to direct our attention away from the individual. ${ }^{20}$ Small relative risk reductions may be important in human terms if they are associated with interventions that we can apply to large populations (such as those who suffer a myocardial infarction) and thus delay many deaths. Peto has used this argument to advance the cause of the large, simple trials that are often necessary to detect small relative risk reductions.

"Patient important," on the other hand, focuses us on the individual clinical encounter and the preeminence of the patient's values and preferences within that encounter.
Alternative terms may be preferable depending on the context of a specific discussion.

In the domain of values and preferences, the central figure in clinical decision making is shifting from the clinician to the patient. Clinicians and investigators may wish to keep in step with this development by focusing not on outcomes that are clinically relevant, but on those that are patient important.

GORDON GUYATT, MD

VICTOR MONTORI, MD

P J DEVEREAUX, MD

HOLGER SCHÜNEMANN, MD

MOHIT BHANDARI, MD

Departments of Medicine and Clinical Epidemiology \& Biostatistics McMaster University Hamilton Ontario, Canada

1 Arora NK, McHorney CA. Patient preferences for medical decision making: who really wants to participate? Med Care 2000;38:335-41.

2 Stapf C, Mohr JP. Ischemic stroke therapy. Annu Rev Med 2002;53:453-75.

3 Inzerillo A, labal J, Troen B, Meier DE. Skeletal fragility in the elderly. In:

Cassel CK, editor. Geriatric medicine: an evidence-based approach. 4th ed. New York: Springer-Verlag, 2003.

4 Echt DS, Liebson PR, Mitchell LB, et al. Mortality and morbidity in patients receiving encainide, flecainide, or placebo. The Cardiac Arrhythmia Suppression Trial. N Engl I Med 1991;324:781-8.

5 Rossouw JE, Anderson GL, Prentice RL, et al. Risks and benefits of estrogen plus progestin in healthy postmenopausal women: principal results From the Women's Health Initiative randomized controlled trial. JAMA 2002;288:321-33.

6 Xamoterol in severe heart failure. The Xamoterol in Severe Heart Failure Study Group. Lancet 1990;336:1-6.

7 Packer M, Carver JR, Rodeheffer RJ, et al. Effect of oral milrinone on mortality in severe chronic heart failure. The PROMISE Study Research Group. N Engl J Med 1991:325:1468-75.

8 Packer M, Rouleau JL, Svedberg K, et al. Effect of flosequinan on survival in chronic heart failure: preliminary results of the PROFILE study. Circulation 1993;88(Suppl I): :-301.

9 Hampton JR, van Veldhuisen DJ, Kleber FX, et al. Randomised study of effect of ibopamine on survival in patients with advanced severe heart failure Second Prospective Randomised Study of Ibopamine on Mortality and Efficacy (PRIME II) Investigators. Lancet 1997:349:971-7.

10 Califf RM, Adams KF, McKenna WJ, et al. A randomized controlled trial of epoprostenol therapy for severe congestive heart failure: The Flolan International Randomized Survival Trial (FIRST). Am Heart $J$ 1997; 134:44-54.

11 Cook'DJ, Guyatt GH, Jaeschke R, et al. Determinants in Canadian health care workers of the decision to withdraw life support from the critically ill. Canadian Critical Care Trials Group. JAMA 1995:273:703-8.

12 Devereaux PJ, Anderson DR, Gardner MJ, et al. Differences between perspectives of physicians and patients on anticoagulation in patients with atrial fibrillation: observational study. BMJ 2001;323:1218-22.

13 Whelan T, Sawka C, Levine M, et al. Helping patients make informed choices: a randomized trial of a decision aid for adjuvant chemotherapy in lymph node-negative breast cancer. J Natl Cancer Inst 2003;95:581-7.

14 Edwards A. Elwyn G. Evidence-based patient choice: inevitable or impossible? New York: Oxford University Press, 2001.

15 Charles C, Gafni A, Whelan T. Decision-making in the physician-patient encounter: revisiting the shared treatment decision-making model. Soc Sci Med 1999;49:651-61.

16 Little P, Everitt H, Williamson I, et al. Preferences of patients for patient centred approach to consultation in primary care: observational study. BM 2001:322:468-72.

17 O'Connor AM, Stacey D, Entwistle V, et al. Decision aids for people facing health treatment or screening decisions. Cochrane Database Syst Rev 2003;(2):CD001431

18 Berger M, Muhlhauser I. Diabetes care and patient-oriented outcomes. JAMA 1999:281:1676-8.

19 Sweeney KG, MacAuley D, Gray DP. Personal significance: the third dimension. Lancet 1998;351:134-6.

20 Early Breast Cancer Trialists' Collaborative Group. Treatment of early breast cancer: volume 1 - worldwide evidence 1985-1990. Oxford: Oxford University Press, 1990 